\title{
Preoperative determination of artificial chordae length with 320-slice computed tomographic images
}

Shohei Yoshida, MD, Koichi Toda, MD, PhD, Shigeru Miyagawa, MD, PhD, Yasushi Yoshikawa, MD, and Yoshiki Sawa, MD, PhD

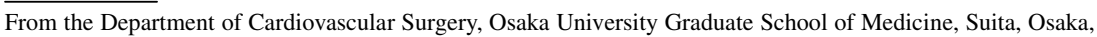
Japan.

Disclosures: Authors have nothing to disclose with regard to commercial support.

Received for publication March 16, 2017; revisions received May 31, 2017; accepted for publication June 26, 2017; available ahead of print July 20, 2017.

Address for reprints: Shohei Yoshida, MD, Department of Cardiovascular Surgery, Osaka University Graduate School of Medicine, 2-2 Yamadaoka, Suita, Osaka 565-0871, Japan (E-mail: s-yoshida@surg1.med.osaka-u. ac.jp).

J Thorac Cardiovasc Surg 2017;154:1634-7

0022-5223/\$36.00

Copyright $\subset 2017$ by The American Association for Thoracic Surgery

http://dx.doi.org/10.1016/j.jtcvs.2017.06.054

$\checkmark$ Video clip is available online.

Mitral valve repair with artificial chordae is an established surgical method for treating severe mitral regurgitation caused by anterior leaflet prolapse or complex pathologies. ${ }^{1}$ It is difficult to determine artificial chordae length preoperatively by means of echocardiography because of its insufficient visibility of papillary muscle (PM); therefore, intraoperative fine adjustment of the artificial chordae site and length, depending on the surgeon's skills, is required. During surgery, cardiac anatomy under cardiac arrest differs from that of the beating heart. ${ }^{1-3}$ It therefore may be important to predict the exact length of

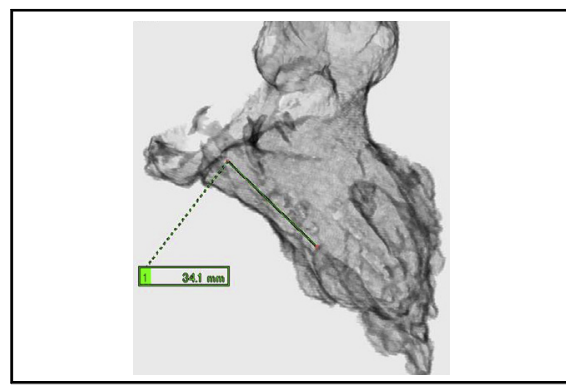

Artificial chordae length was predicted with computed tomographic images.

\section{Central Message}

The computed tomographic images could accurately predict the artificial chordae length, which may contribute to the development of mitral valve repair toward minimally invasive surgery.

See Editorial Commentary page 1638.

See Editorial page 1632. the artificial chordae for the beating heart to develop mitral valve repair in the direction of minimally invasive surgery. ${ }^{4,5}$

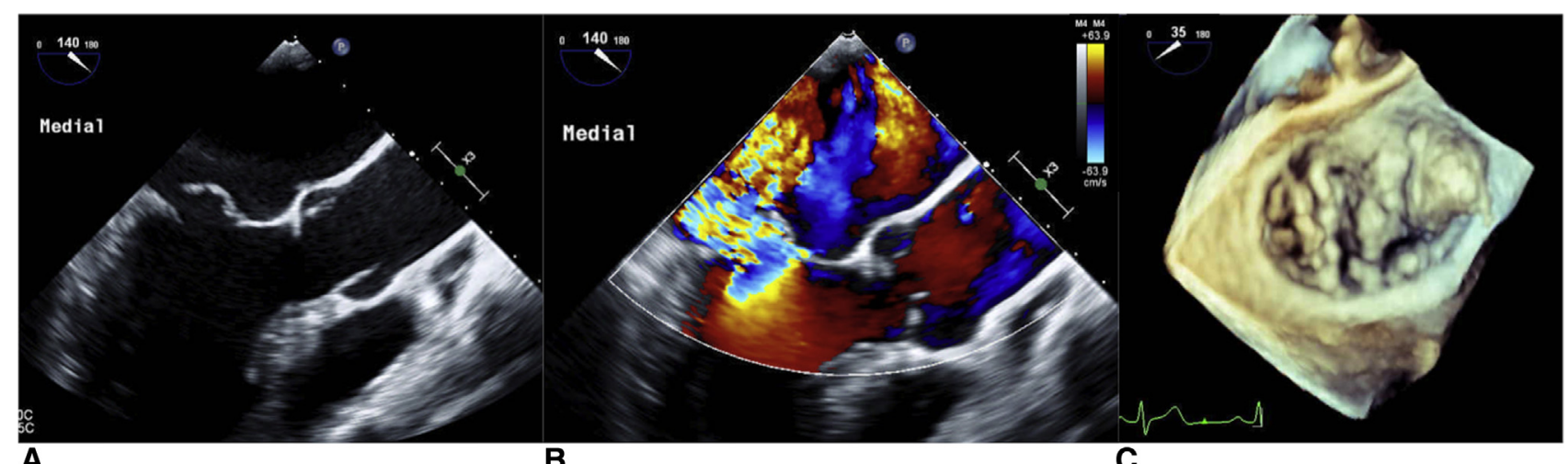

A

B

C

FIGURE 1. Preoperative transesophageal echocardiography images. A, The image without color Doppler in the long-axis view shows the prolapse of the anterior mitral leaflet. The volumetry revealed that the left ventricular end-diastolic volume was $216 \mathrm{~mL}$, and the left ventricular end-systolic volume was $73 \mathrm{~mL}$. B, The image with color Doppler in the long-axis view shows the associated severe mitral regurgitation. C, The 3-dimensional image exhibits the prolapse of the medial side of the anterior mitral leaflet. 

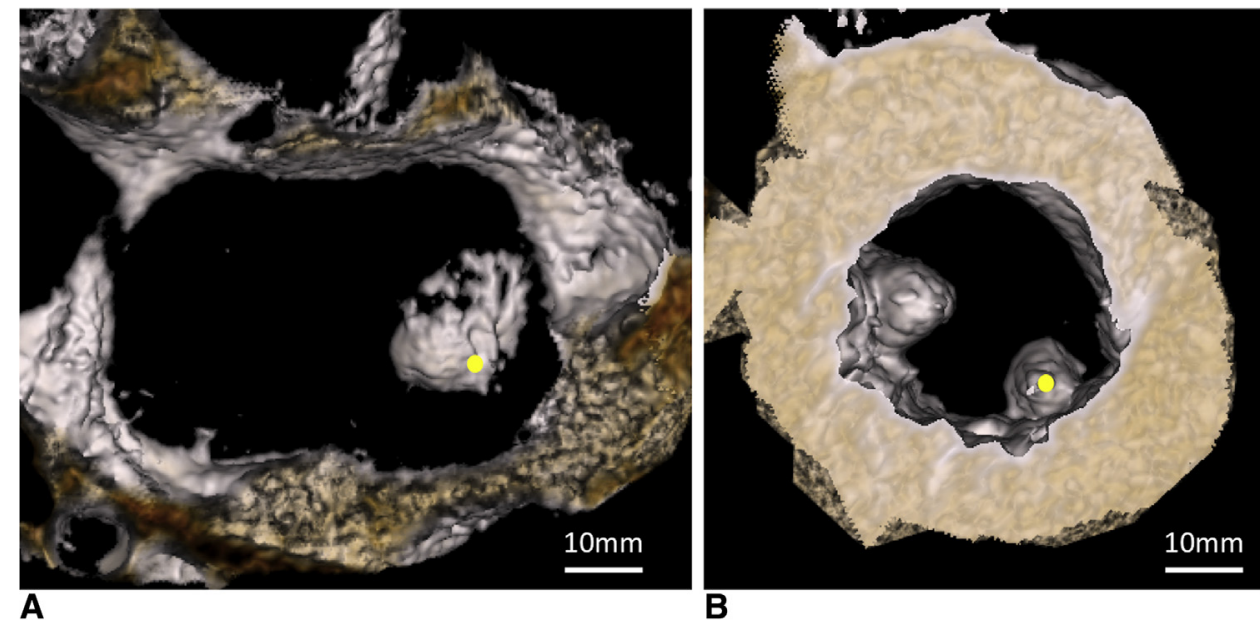

FIGURE 2. From the computed tomographic images, 3-dimensional images were reconstructed. A, The image reconstructed in the surgeon's view reveals prolapse of the medial side of the anterior mitral leaflet. The center of the prolapse area was determined as an attachment site of the artificial chordae (yellow dot). B, The image, reconstructed in the same view, reveals that this patient had an anterolateral and posteromedial papillary muscle. The posteromedial papillary muscle was determined as an attachment site of the artificial chordae (yellow dot).

We accurately predicted the artificial chordae length in 15 patients (median, $22 \mathrm{~mm}$; range, 16-34 $\mathrm{mm}$ ) by using a dedicated workstation for data analysis (AZE Virtual Place, AZE, Tokyo, Japan) with 320-slice cardiac computed tomographic images. We present the case of 40-year-old man with severe mitral regurgitation caused by anterior leaflet prolapse resulting in left ventricular dilatation (Figure 1, A-C). First, we identified the prolapse area in the anterior leaflet, which required the artificial chordae to be attached to the center of the prolapse area in parallel direction to the coaptation line (Figure 2, A, yellow dot).
Second, we evaluated the PMs, finding a major head of each PM, and determined that the posteromedial PM was an appropriate attachment site in this case (Figure 2, B, yellow dot; and Video 1). Finally, the length between the 2 planned attachment points, the head of the posteromedial PM and the opposite point in the healthy posterior mitral leaflet, was measured as $34 \mathrm{~mm}$ from both 2- and 3dimensional images (Figure 3, $A-C$ ). In surgery, the loop technique with a $29-\mathrm{mm}$ loop and a 5-mm knot was used for reconstruction of the artificial chordae, resulting in successful repair with annuloplasty (Figure $4, A$ and $B$ ).

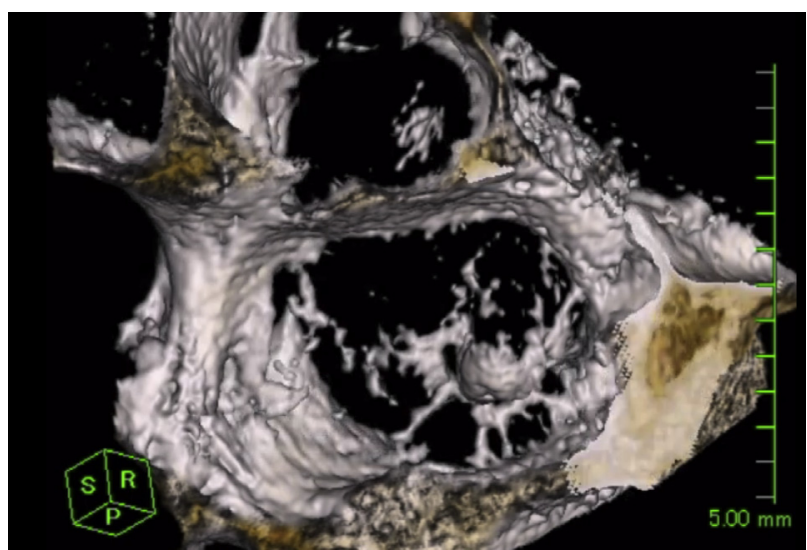

VIDEO 1. The 3-dimensional video was reconstructed from the computed tomographic images. First, the left atrium and the mitral valve in the surgeon's view are revealed. Subsequently, the left ventricular myocardium and the papillary muscle are displayed. Video available at: http://www.jtcvsonline.org/ article/S0022-5223(17)31373-9/addons. 


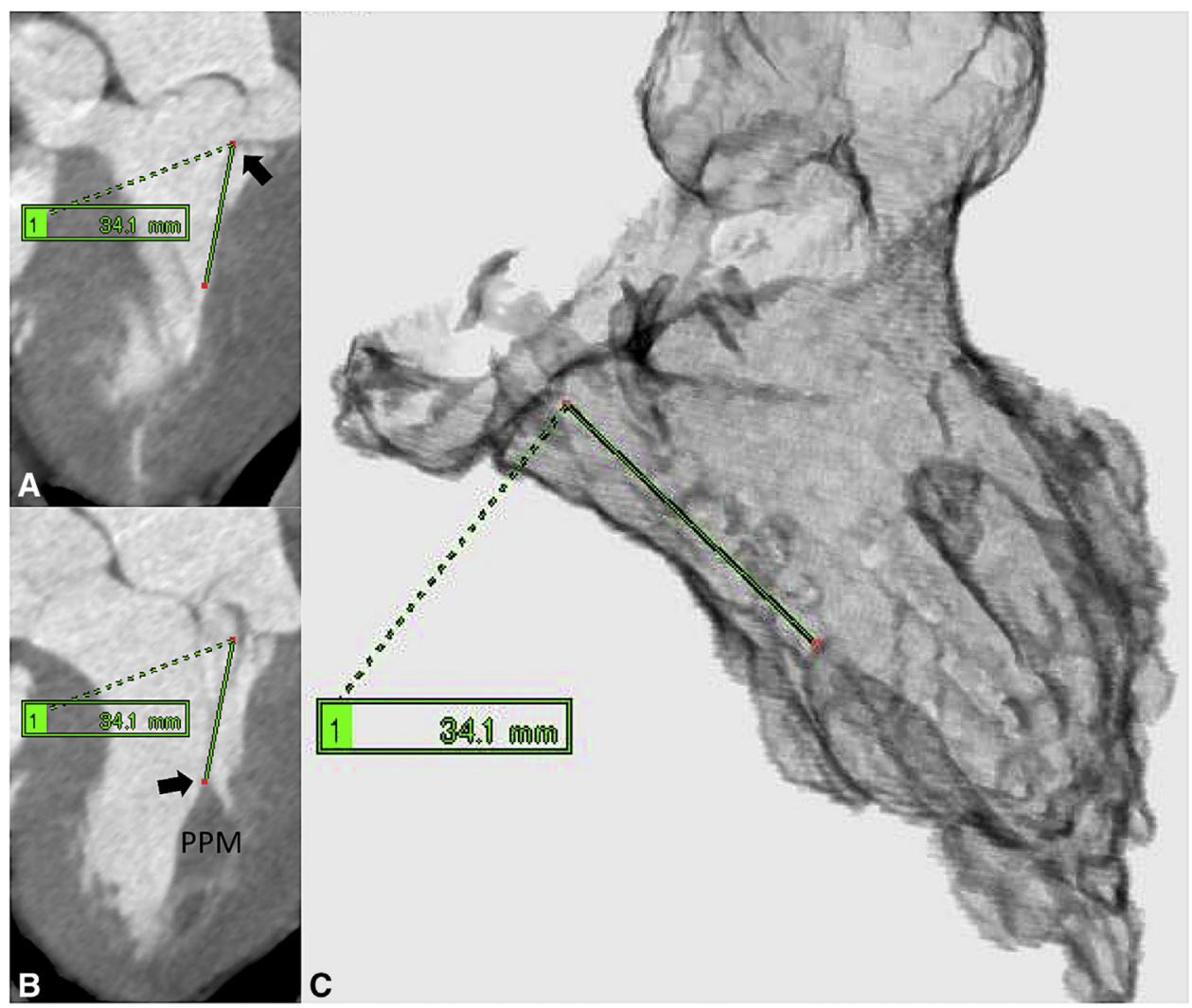

FIGURE 3. The length between the 2 planned attachment points of the artificial chordae, the head of the posteromedial papillary muscle and the opposite point in the healthy posterior mitral leaflet, was measured by means of both 2- and 3-dimensional images. A, The planned attachment point of the artificial chordae in the posterior mitral leaflet was determined (black arrow). B, The planned attachment point of the artificial chordae in the posteromedial papillary muscle $(P P M)$ was determined (black arrow). C, The planned artificial chordae attachment is shown in a 3-dimensional image.

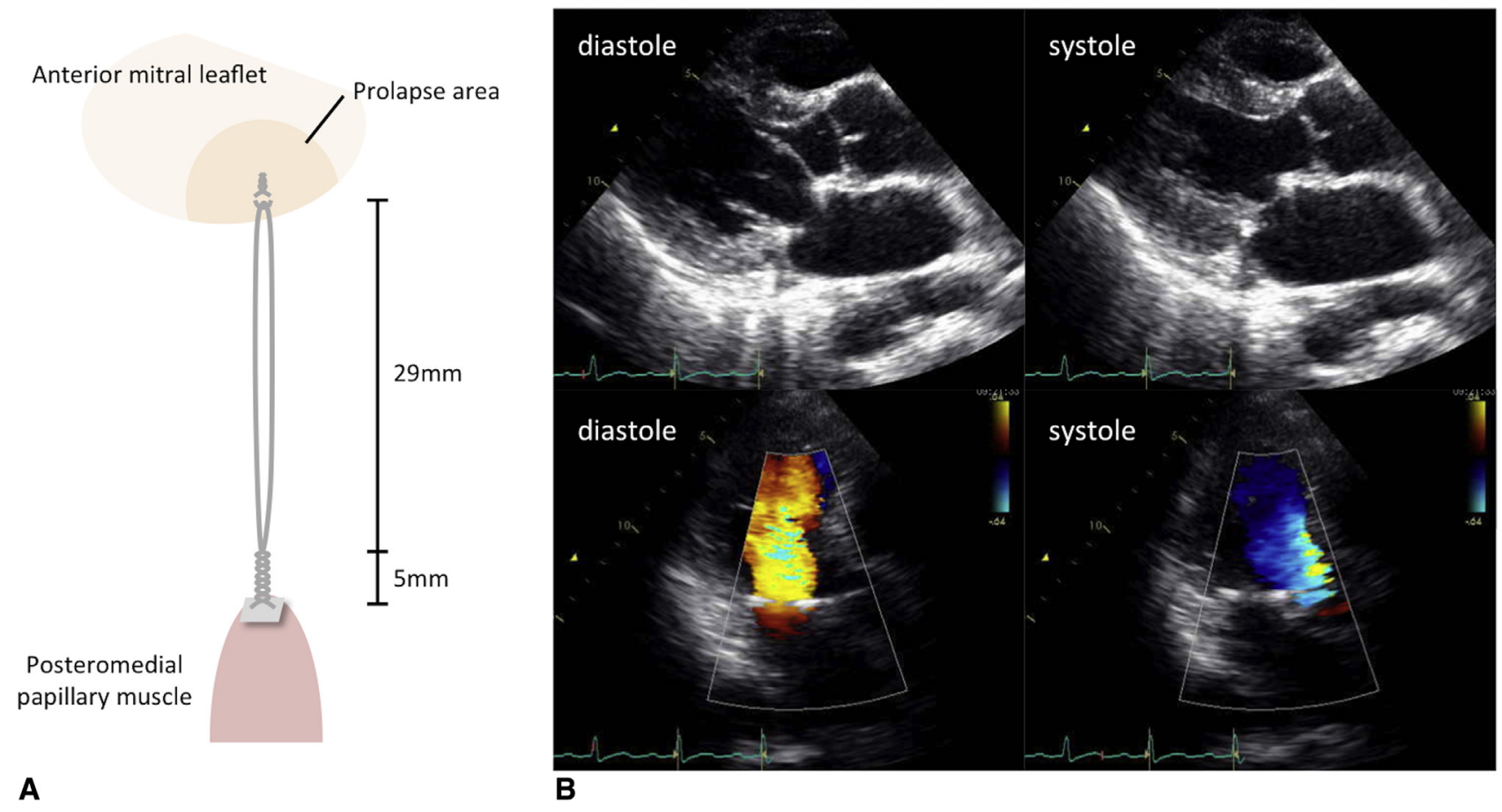

FIGURE 4. A, The illustration represents the loop reconstruction with a 29-mm loop and 5-mm knot. B, Postoperative echocardiographic image shows an appropriate height of the anterior leaflet and a sufficient coaptation length of $10 \mathrm{~mm}$. 


\section{References}

1. Huang HL, Xie XJ, Fei HW, Xiao XJ, Liu J, Zhuang J, et al. Realtime three-dimensional transesophageal echocardiography to predict artificial chordae length for mitral valve repair. J Cardiothorac Surg. 2013; $8: 137$.

2. Ibrahim M, Rao C, Savvopoulou M, Casula R, Athanasiou T. Outcomes of mitral valve repair using artificial chordae. Eur J Cardiothorac Surg. 2014; 45:593-601.

3. Chen X, Sun D, Yang J, Feng W, Gu T, Zhang Z, et al. Preoperative assessment of mitral valve prolapse and chordae rupture using real time three-dimensional transesophageal echocardiography. Echocardiography. 2011;28:1003-10.

4. Suri RM, Dearani JA, Mihaljevic T, Chitwood WR Jr, Murphy DA, Trento A, et al. Mitral valve repair using robotic technology: safe, effective, and durable. J Thorac Cardiovasc Surg. 2016;151:1450-4.

5. Lamelas J, Nguyen TC. Minimally invasive valve surgery: when less is more. Semin Thorac Cardiovasc Surg. 2015;27:49-56. 